Received: 16 April 2018

Accepted: 28 September 2018

Published online: 12 October 2018
NTIFIC REP

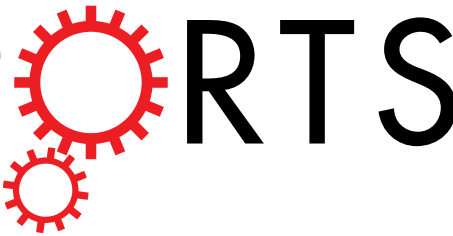

OPEN

Degradation kinetics of Ti-Cu compound layer in transient liquid phase bonded graphite/copper joints

\author{
Jincheng Lin, Mei Huang, Weiqi Yang \& Lili Xing
}

The continuous Ti-Cu compound layer produced in brazing of graphite to copper with Ti foil is found to be seriously detrimental to joint properties due to its brittleness. In this work, a transient liquid phase (TLP) bonding method with a diffusion process below melting point is developed to realize a Ti-Cu compound layer free joint. The degradation of Ti-Cu compound layer depends on two simultaneously occurring processes, namely flow of titanium atoms to copper substrate and that to TiC layer on graphite. The latter is determined by growth kinetics of TiC layer based on carbon diffusion process. A degradation model is proposed and applied to optimize the TLP bonding. The improved graphite/ copper joints without Ti-Cu compound layer show $20.8 \%$ higher in shear strength compared with that of brazing joints.

Carbon based materials (CBMs) including graphite and carbon fiber reinforced carbon composites have been widely used as structural materials and electronic components owing to their unique combination of high melting point, high thermal/electrical conductivity, excellent thermal fatigue and plasma compatibility ${ }^{1-4}$. In most practical applications, CBMs requires joining with metal, especially copper or copper alloy, to form complete structures with desirable and unique characteristics such as resistance to physical/radiation damage, abrasion resistance, higher strength and toughness ${ }^{5}$. For example, the fabrication of divertor in ITER involves joining of plasma facing materials (PFMs, including CBMs and tungsten) to copper based heat sink ${ }^{6}$. In electromechanical industry, the commutator integrated by graphite and copper fittings has high lubrication and abrasion resistance. The quality of graphite/copper joint is an important indicator to the performance and service life of D.C. motor ${ }^{7,8}$.

For joining of CBMs to copper, brazing is the most commonly used technique due to its simplicity, low cost and good adaptability to different joint shapes. Because copper is inert to carbon characterized by neither with mutual solubility nor formation of stable carbides ${ }^{9}$, some strong carbide-forming element like titanium is usually added in filler alloy to facilitate reactive wetting. In the past decade, various active brazing alloys (such as $\mathrm{Cu} 50 \mathrm{TiH}_{2}{ }^{10}, \mathrm{Cu}-\mathrm{ABA}^{11}, \mathrm{TiCuNi}^{6}$ ) have been used to join $\mathrm{CBMs}$ and copper. For these brazing alloys, the content of Ti is a key factor for joint quality. Generally, Ti concentration is inversely proportional to contact angles of liquid alloy. It's reported that the wetting on CBMs requires the addition of Ti at least 10 at.\% so as to offset the influences of pre-oxidation or possible pollution on substrate surface 9 . Nevertheless, excessive Ti may lead to abundant intermetallic compounds (IMCs) in seam. Since residual stress caused by the mismatch of coefficient of thermal expansion (CTE) between CBMs and copper is easily created in the joint, the brittle IMCs dramatically increase the possibility of joint failure in service ${ }^{12-14}$. Thus, how to solve the conflict between wetting and IMCs-forming tendency is essential to the property improvement of CBMs/copper joints.

In this work, the graphite is successfully joined to copper by improved transient liquid phase (TLP) bonding with Ti interlayer. It's known that typical TLP bonding involves long isothermal solidification process at joining temperature to make sufficient diffusion of the interlayer element (or a constituent of an alloy interlayer) into substrate materials ${ }^{15,16}$. But in our method, the contact reaction between $\mathrm{Ti}$ and $\mathrm{Cu}$ is first carried out at $920^{\circ} \mathrm{C}$ to promote wetting, then isothermal process $\left(\right.$ at $860^{\circ} \mathrm{C}$ ) is set below the melting point so as to prevent sever infiltration of liquid alloy into graphite. In the solid isothermal process, $\mathrm{Ti}$-Cu IMCs produced in the contact reaction can dissolve by two ways: the first is diffusion of Ti to $\mathrm{Cu}$ substrate and the second is competing reactions with

Sino-French Institute of Nuclear Engineering and Technology, Sun Yat-sen University, Zhuhai, 519082, P. R. China. Correspondence and requests for materials should be addressed to W.Y. (email: yangweiqi@mail.sysu.edu.cn) or L.X. (email: xinglili@mail.sysu.edu.cn) 
(a)

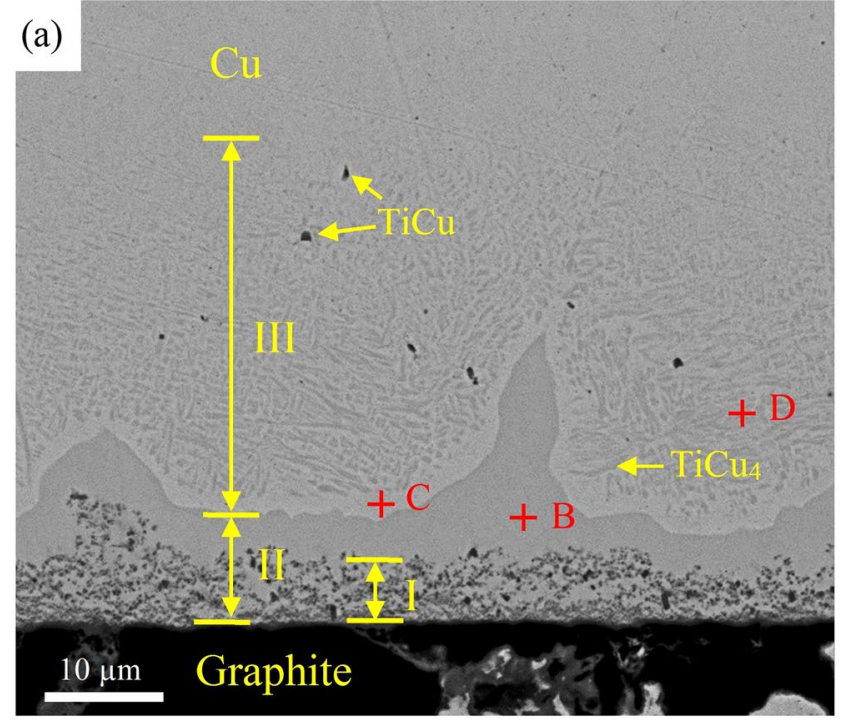

Figure 1. Backscattered electron micrographs of graphite/ $\mathrm{Ti}(50 \mu \mathrm{m}) / \mathrm{Cu}$ joint brazed at $920^{\circ} \mathrm{C}$ for $10 \mathrm{~min}$. (a) Microstructure of the joint. (b) Interfacial reaction layer on graphite. (c) Fillet of the joint.

\begin{tabular}{|l|l|l|l|l|}
\hline \multirow{3}{*}{ Points } & \multicolumn{3}{|l|}{ Elements (at.\%) } & \multirow{2}{*}{ Possible Phase } \\
\cline { 2 - 4 } & $\mathrm{Cu}$ & $\mathrm{Ti}$ & $\mathrm{C}$ & (i \\
\hline A & 3 & 42 & 55 & $\mathrm{TiC}$ \\
\hline B & 79 & 21 & - & $\mathrm{TiCu}_{4}$ \\
\hline C & 97 & 3 & - & $\mathrm{Cu}_{\mathrm{ss}}$ \\
\hline D & 90 & 10 & - & $\mathrm{TiCu}_{4}+\mathrm{Cu}_{\mathrm{ss}}$ \\
\hline
\end{tabular}

Table 1. EDS analysis of the zones identified in Fig. 1.

TiC layer at graphite interface. The degradation of Ti-Cu IMCs is governed both by Ti diffusion behavior and TiC growth kinetics. The degradation model proposed by this work can be used to predict the residual IMCs layer in seam and is helpful to improve the joining technique.

This paper is divided into three parts. In the first one, the microstructure of joint after contact reaction is characterized and the brittle IMCs layer is identified. In the second part, the experimental results as well as calculations on degradation kinetics of Ti-Cu IMCs layer are shown and discussed. In the third part, the microstructure and mechanical properties of graphite/copper joint joined by an optimized TLP bonding are presented.

\section{Results and Discussion}

Microstructure of graphite/Cu joint brazed with Ti interlayer. The graphite/Cu brazing involves a series of interfacial reactions in seam. During heating, solid-state diffusion reactions occur first between Ti interlayer and $\mathrm{Cu}$ substrate, producing a small quantity of $\mathrm{Ti}-\mathrm{Cu}$ compounds, such as $\mathrm{TiCu}, \mathrm{Ti}_{3} \mathrm{Cu}_{4}$ and $\mathrm{TiCu}_{4}$. As the temperature rises above the eutectic point $\left(875^{\circ} \mathrm{C}\right)$, the $\mathrm{Cu}$-Ti eutectic liquid forms and fills the gap between graphite and $\mathrm{Cu}$ by capillarity. The wetting process on graphite accompanies fast growing of TiC layer at graphite/ liquid interface. Besides, mutual diffusion between $\mathrm{Ti}$ and $\mathrm{Cu}$ results in enrichment of $\mathrm{Cu}$ in $\mathrm{Cu}$-Ti liquid. So in cooling process, the peritectic reaction (Liquid $+\mathrm{Cu} \rightarrow \mathrm{TiCu}_{4}$ ) happens and a continuous $\mathrm{TiCu}_{4}$ layer forms in the joint.

Figure 1 shows the microstructure of graphite/Cu joint brazed at $920^{\circ} \mathrm{C}$ for $10 \mathrm{~min}$. Three regions can be distinguished in the joint. Region I is comprised by a thin $\mathrm{TiC}$ layer (point $\mathrm{A}$ in Table 1 ) and nanoparticle layer (as shown in Fig. 1b). It's inferred small amount of carbon atoms diffuse through $\mathrm{TiC}$ layer and dissolve into the $\mathrm{Cu}$-Ti liquid. Subsequently, $\mathrm{TiC}$ particles precipitate out of the liquid. Region II is the continuous $\mathrm{TiCu}_{4}$ layer (point B) produced by peritectic reaction. Region III is the transition layer from brazing liquid to $\mathrm{Cu}$ substrate. As the solubility of $\mathrm{Ti}$ in $\mathrm{Cu}$ significantly decreases during cooling, lath like $\mathrm{TiCu}_{4}$ phases precipitate from the supersaturate $\mathrm{Cu}_{\mathrm{ss}}$ (point $\mathrm{C}$ ) to form this two-phase region $\left(\mathrm{TiCu}_{4}+\mathrm{Cu}_{\mathrm{ss}}\right.$, point $\mathrm{D}$ ). It is noticed that some 


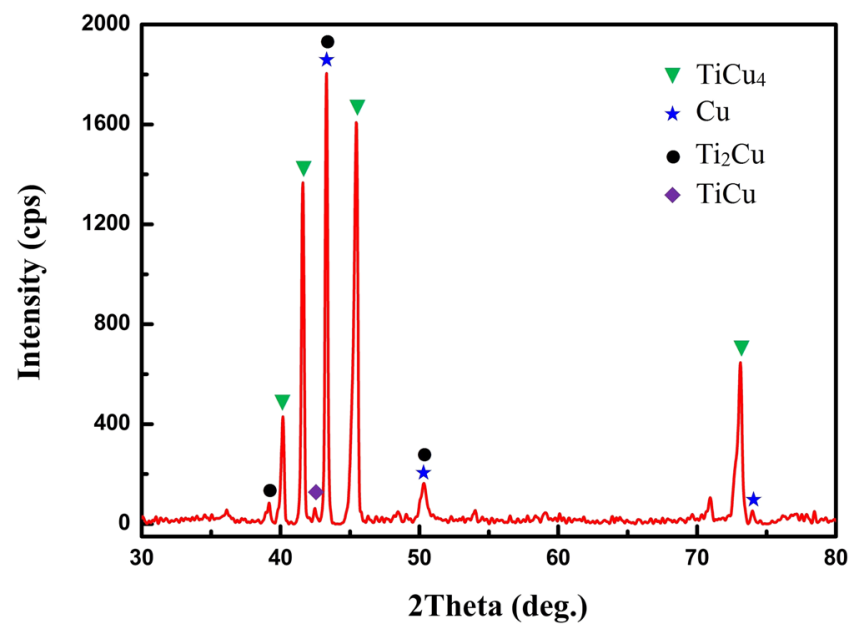

Figure 2. XRD pattern of graphite/Ti $(50 \mu \mathrm{m}) / \mathrm{Cu}$ joint plane.

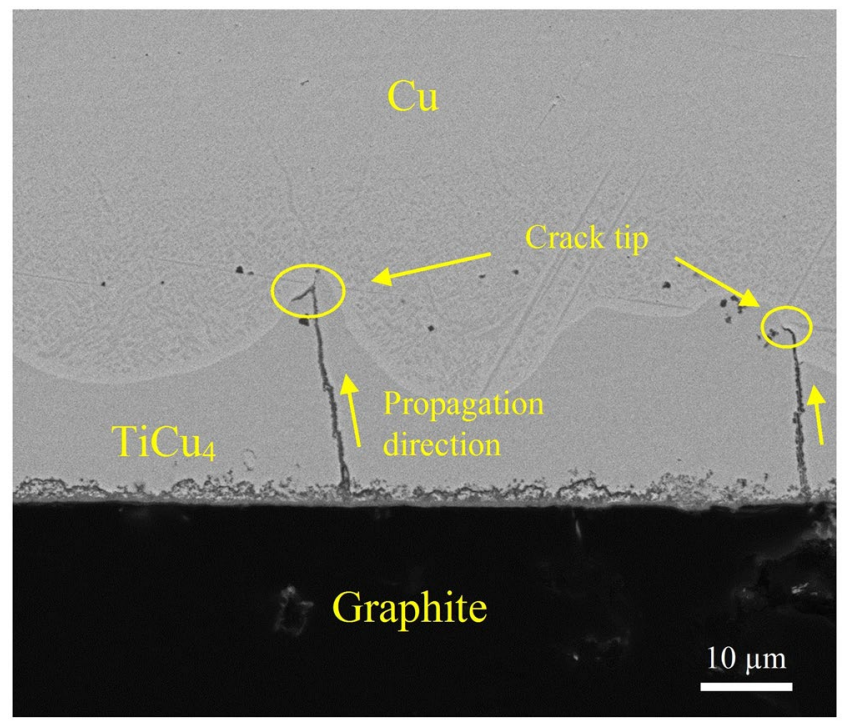

Figure 3. Microstructure of graphite/Ti $(50 \mu \mathrm{m}) / \mathrm{Cu}$ joint after one week's standing without any load.

dark TiCu blocks are also found in this layer. As mentioned above, various $\mathrm{Ti}-\mathrm{Cu}$ compounds are produced by solid-state reactions during heating. But after the melting of $\mathrm{Ti}$ interlayer, majority $\mathrm{Ti}$ - $\mathrm{Cu}$ compounds dissolve in the liquid except for the thermodynamically stable $\mathrm{TiCu}\left(\Delta \mathrm{G}=-17530+3.37 \mathrm{~T} \mathrm{~J} / \mathrm{mol}^{17}\right)$. Although most $\mathrm{TiCu}$ blocks can be extruded to the fillet (as shown in Fig. 1c) by liquid flow, small amount of TiCu are still left in the seam. Figure 2 is the XRD patterns of joint plane prepared by polishing layer by layer. It confirms the existence of $\mathrm{TiCu}_{4}$ and $\mathrm{TiCu}$.

As indicated in Fig. 1a, it seems that the joints brazed with Ti interlayer are metallurgically sound and defect free. However, after one week's standing without any load, cracks were widely found in all samples as shown in Fig. 3. These cracks initiate in graphite interface, propagate vertically through $\mathrm{TiCu}_{4}$ layer and stop in $\mathrm{Cu}_{\mathrm{ss}}$ in region III. Obviously, the residual stress resulted from large mismatch of CTE between the two dissimilar substrates $\left(\alpha_{\mathrm{Cu}}=16.5 \times 10^{-6} \mathrm{~K}^{-1}, \alpha_{\text {graphite }}=3.9 \times 10^{-6} \mathrm{~K}^{-1}\right)$ is the main reason for cracking. In graphite/Cu joints, $\mathrm{Cu}$ will be under tension and the graphite under compression during cooling from brazing temperature ${ }^{18}$. The elastic residual stress in Cu substrate, roughly estimated by $\sigma=E \Delta \alpha \Delta T$ ( $E$ : Young's module, $\Delta \alpha$ : CTE mismatch, $\Delta T$ : temperature interval $)^{19}$, is $1416 \mathrm{MPa}$, which exceeds the yield strength of $\mathrm{Cu}$. In region III of the seam, stress can be released by deformation of $\mathrm{Cu}_{\mathrm{ss}}$. But in region II, fracture rather than plastic deformation is more likely to happen in the brittle Ti-Cu compounds. This hidden danger may lead to a catastrophic consequence when the joint serves in alternating stress environments. Thus, how to eliminate the $\mathrm{Ti}$-Cu compounds, especially the thick continuous $\mathrm{TiCu}_{4}$ layer, is a key issue in practical application.

Degradation kinetics of Ti-Cu compound layer in TLP bonding. In order to realize a Ti-Cu compound layer free joint, TLP bonding approach is proposed and the degradation of Ti-Cu compound layer is 

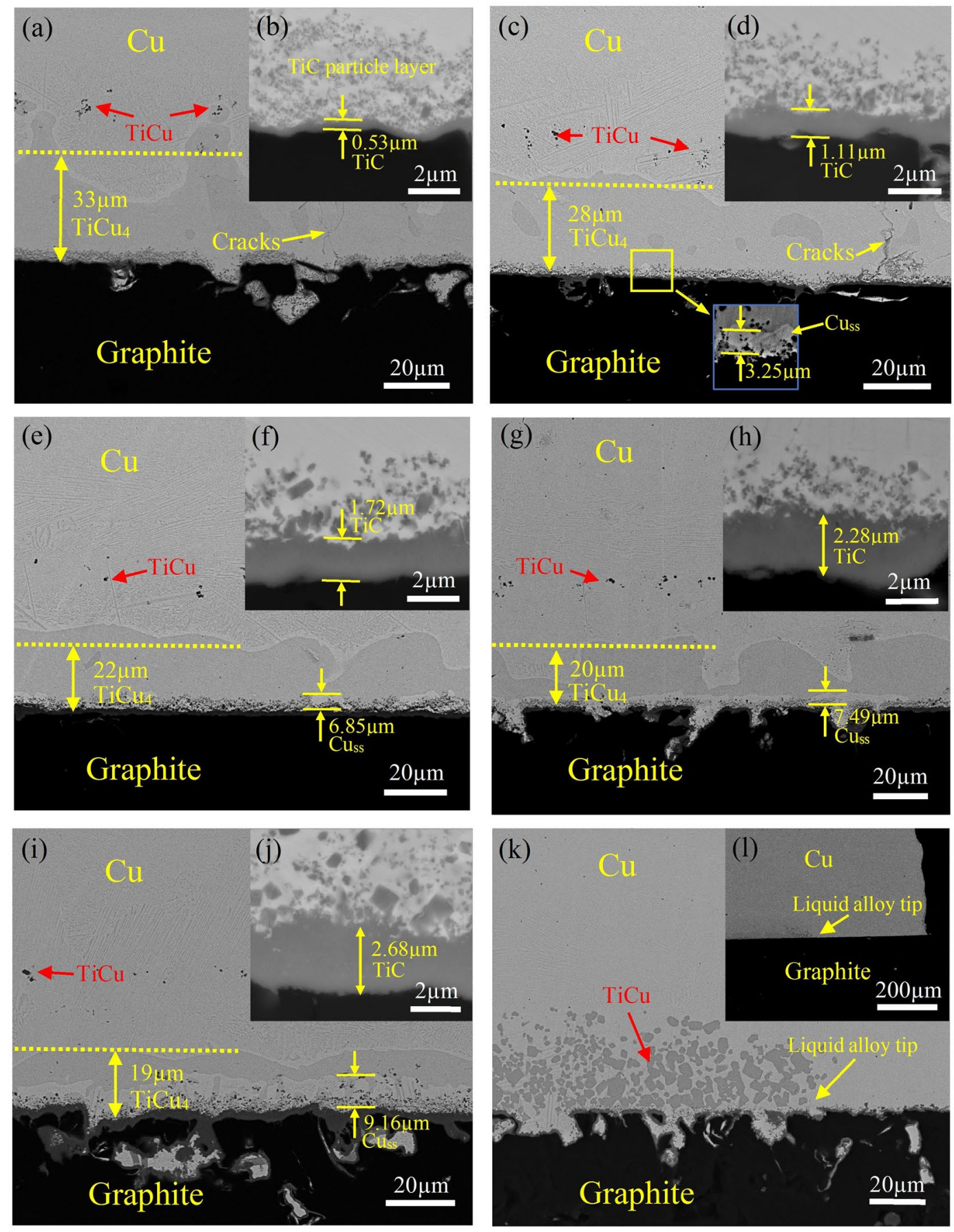

Figure 4. Backscattered electron micrographs of graphite/Ti $(4 \mathrm{~mm} \times 4 \mathrm{~mm} \times 20 \mu \mathrm{m}) / \mathrm{Cu}$ joints prepared by TLP bonding with various holding time at $860^{\circ} \mathrm{C}$. (a) $0 \mathrm{~h}$. (b) Interfacial region of (a). (c) $1 \mathrm{~h}$. (d) Interfacial region of (c). (e) $3 \mathrm{~h}$. (f) Interfacial region of (e). (g) $4.5 \mathrm{~h}$. (h) Interfacial region of (g). (i) $6 \mathrm{~h}$. (j) Interfacial region of $(\mathbf{i})$. (k,l) Boundary of the joint shown in (a).

studied by using a smaller $4 \mathrm{~mm} \times 4 \mathrm{~mm} \times 20 \mu \mathrm{m}$ titanium interlayer. Figure 4 shows the microstructure of graphite/Cu joints with solid diffusion times of $0,1,3,4.5$ and 6 hours. It is observed that TiCu compounds formed before melting are nearly at the same distance to graphite interface regardless of variation of holding time. The stable positions of TiCu reflect the low fluidity of brazing melt. Besides, Fig. 4k and 1 show that the Ti-Cu melts are trapped in the seam and no extrusion happens. In this condition, the continuous $\mathrm{TiCu}_{4}$ layer just after melting is around $34 \mu \mathrm{m}$ thick. As holding time extended, the thickness of $\mathrm{TiCu}_{4}$ layer decreases while the thickness of region III $\left(\mathrm{Cu}_{\mathrm{ss}}+\mathrm{TiCu}_{4}\right)$ increases. Apparently, the diffusion of Ti to $\mathrm{Cu}$ substrate at high temperature consumes $\mathrm{TiCu}_{4}$ and forms a supersaturated solid solution region in $\mathrm{Cu}$ substrate. Another way leading to the reduction of $\mathrm{TiCu}_{4}$ layer is the growth of $\mathrm{TiC}$ on graphite. As $\mathrm{TiC}$ is far more thermodynamically stable than $\mathrm{TiCu}_{4}$ $\left(\Delta \mathrm{G}_{\mathrm{TiCu} 4}=-7600+3.12 \mathrm{~T} \mathrm{~J} / \mathrm{mol}^{20}\right)$, the Ti atoms required for growth of TiC nearly all come from dissolving of 


\begin{tabular}{|l|l|l|l|l|}
\hline \multirow{2}{*}{$\begin{array}{l}\text { Diffusion } \\
\text { times at } \mathbf{8 6 0}^{\circ} \mathbf{C}\end{array}$} & \multicolumn{2}{|l|}{$\mathbf{T i C u}_{4}$ layer thickness $(\mu \mathrm{m})^{*}$} & \multicolumn{2}{|l|}{ TiC layer thickness $(\mu \mathrm{m})$} \\
\hline 0 & Average & SD & Average & SD \\
\hline $0 \mathrm{~h}$ & 32.86 & 9.26 & 0.53 & 0.05 \\
\hline $1 \mathrm{~h}$ & 27.92 & 2.42 & 1.11 & 0.22 \\
\hline $3 \mathrm{~h}$ & 21.98 & 3.62 & 1.72 & 0.23 \\
\hline $4.5 \mathrm{~h}$ & 20.11 & 6.86 & 2.28 & 0.25 \\
\hline $6 \mathrm{~h}$ & 19.03 & 2.71 & 2.68 & 0.32 \\
\hline
\end{tabular}

Table 2. The thickness of $\mathrm{TiCu}_{4}$ and $\mathrm{TiC}$ layer in graphite/copper joints. *Measuring from the graphite/TiC interface to $\mathrm{TiCu}_{4} /$ Cuss interface.

$\mathrm{TiCu}_{4}\left(\mathrm{TiCu}_{4} \rightarrow \mathrm{Ti}+4 \mathrm{Cu}\right)$. Figure 4 shows that, with extension of holding time, the thickness of TiC layer gradually increases while the boundary of $\mathrm{TiCu}_{4}$ layer recedes, leaving a narrow $\mathrm{Cu}_{\mathrm{ss}}$ layer as a decomposition product between $\mathrm{TiCu}_{4}$ and $\mathrm{TiC}$.

In order to quantitatively predict the dissolving rate of $\mathrm{TiCu}_{4}$ layer, a diffusion model is developed in terms of error function solutions for Fick's second law. The present joint involves three interfaces at the beginning: graphite/TiC interface, $\mathrm{TiC} / \mathrm{TiCu}_{4}$ interface and $\mathrm{TiCu}_{4} / \mathrm{Cu}_{\mathrm{ss}}$ interface. The diffusion of $\mathrm{Ti}$ into $\mathrm{Cu}$ substrate and growth of $\mathrm{TiC}$ layer can both lead to dissolving of $\mathrm{TiCu}_{4}$ layer. But considering the two processes occur independently at different sides of $\mathrm{TiCu}_{4}$ layer, the quantity of $\mathrm{TiCu}_{4}$ consumed on the side of $\mathrm{Cu}$ substrate is evaluated by measuring from the graphite/ TiC interface to $\mathrm{TiCu}_{4} / \mathrm{Cu}_{\mathrm{ss}}$ interface (as shown in Table 2).

The Fick's second law of diffusion, relating the changes in concentration of Ti with time and location is:

$$
\frac{\partial c}{\partial t}=D \frac{\partial^{2} c}{\partial x^{2}}
$$

where $D$ is the diffusion coefficient, $c$ is the concentration, $t$ is diffusion time and $x$ is distance. The copper substrate is considered as semi-infinite medium and the $\mathrm{TiCu}_{4} / \mathrm{Cu}_{\mathrm{ss}}$ interface is treated as the not-moving planar boundary. In Ti-Cu system, $\mathrm{TiCu}_{4}$ has a narrow stoichiometric range. Thus, at the $\mathrm{TiCu}_{4} / \mathrm{Cu}_{\mathrm{ss}}$ boundary, the $\mathrm{Ti}$ fraction in $\mathrm{TiCu}_{4}$ is assumed to have the lowest value based on Ti-Cu binary diagram ${ }^{21}$ and the solid solubility of $\mathrm{Ti}$ in $\mathrm{Cu}$ is saturated $\left(6.5\right.$ at.\%) at $860^{\circ} \mathrm{C}$. Due to the small concentration difference of $\mathrm{Ti}$ in $\mathrm{Cu}$, it is assumed that the diffusion coefficient of $\mathrm{Ti}$ is independent of the concentration in $\mathrm{Cu}$ substrate. With these assumptions, the initial and boundary conditions can be written as:

Initial condition $(t=0)$

$$
c(t=0, x \geq 0)=0
$$

Boundary conditions $(t>0)$

$$
\begin{gathered}
c(t>0, x=0)=c_{\mathrm{Ti}, \max }^{\mathrm{Cu}_{\mathrm{ss}}} \\
c(t>0, x=\infty)=0
\end{gathered}
$$

Here $c_{\mathrm{Ti} \text {,max }}^{\mathrm{Cu}_{\mathrm{ss}}}$ and $c$ represent $\mathrm{Ti}$ atomic concentration $\left(\right.$ atoms $\left./ \mathrm{cm}^{3}\right)$ in $\mathrm{Cu}_{\mathrm{ss}}$ at $\mathrm{TiCu}_{4} / \mathrm{Cu}_{\mathrm{ss}}$ interface and $\mathrm{Cu}$ substrate, respectively. The concentration of Ti could be converted from its atomic fraction $(x)$ by

$$
c=\frac{x \rho \mathrm{n} N_{A}}{M}
$$

Where $\rho$ and $M$ are density and molar mass of matrix, respectively. $N_{A}$ is Avogadro constant $\left(N_{A}=6.022 \times 10^{23}\right)$ and $n$ is the atom number per matrix molecule. In copper solid solution, $\rho$ and $M$ are approximate to that of pure $\mathrm{Cu}\left(\rho=8.93 \mathrm{~g} / \mathrm{cm}^{3}\right)^{22}$. So the Ti concentration in saturated $\mathrm{Cu}_{\mathrm{ss}}(6.5 \mathrm{at} . \% \mathrm{Ti})$ is calculated as $c_{\mathrm{Ti} \text {,max }}^{\mathrm{Cu}_{\mathrm{ss}}}=5.46 \times 10^{21}$ atom $/ \mathrm{cm}^{3}$. The solution for Ti concentration in $\mathrm{Cu}$ satisfying Eqs (1-4) can be written as:

$$
c(x, t)=c_{\mathrm{Ti}, \max }^{\mathrm{Cu}_{\mathrm{ss}}}\left[1-\operatorname{erf}\left(\frac{x}{2 \sqrt{D_{\mathrm{Ti}}^{\mathrm{Cu}} t}}\right)\right]
$$

$D_{\mathrm{Ti}}^{\mathrm{Cu}}$ is the titanium diffusion coefficient in copper. So the flow of $\mathrm{Ti}$ atoms $\left(J_{\mathrm{Ti}}\right)$ passing though $\mathrm{TiCu}_{4} / \mathrm{Cu}$ interface can be given as

$$
J_{\mathrm{Ti}}(x=0)=-D_{\mathrm{Ti}}^{\mathrm{Cu}} \frac{\partial c(x=0, t)}{\partial x}=c_{\mathrm{Ti}, \max }^{\mathrm{Cu}_{\mathrm{ss}}} \sqrt{\frac{D_{\mathrm{Ti}}^{\mathrm{Cu}}}{\pi t}}
$$

In isothermal process, it is assumed that $\mathrm{Ti}$ atoms from dissolved $\mathrm{TiCu}_{4}$ all diffuse into $\mathrm{Cu}$ substrate. Applying the rule of atom conservation at the interface, one can write, 


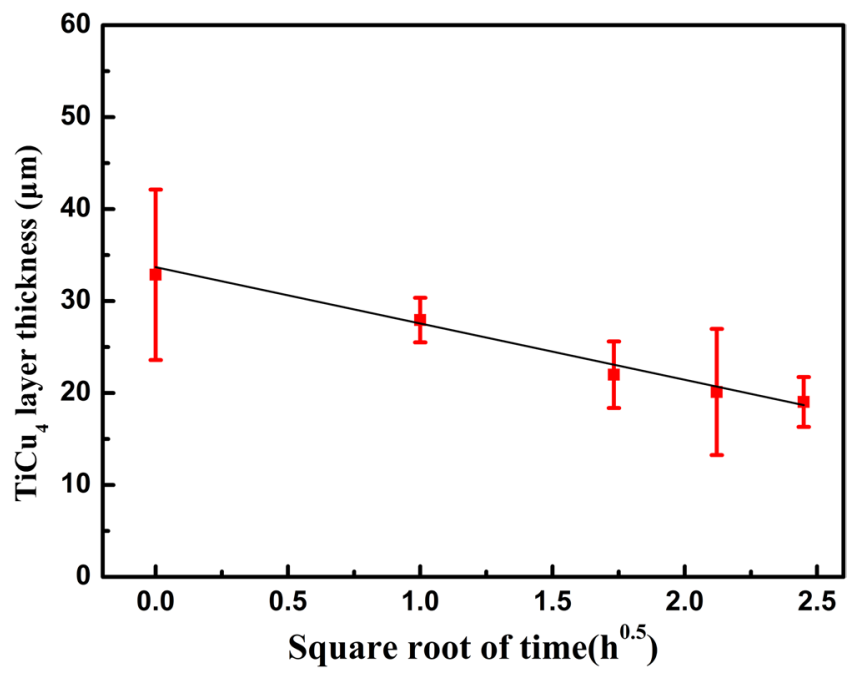

Figure 5. $\mathrm{TiCu}_{4}$ layer thickness as a function of holding time at $860^{\circ} \mathrm{C}$.

$$
\left(c_{\mathrm{Ti}, \min }^{\mathrm{TiCu}_{4}}-c_{\mathrm{Ti}, \max }^{\mathrm{Cu}_{\mathrm{ss}}}\right) \frac{d w}{d t}=-J_{\mathrm{Ti}}(x=0)
$$

where $w$ represents the thickness of $\mathrm{TiCu}_{4}$ layer (by measuring from the graphite/TiC interface to $\mathrm{TiCu}_{4} / \mathrm{Cu}_{\mathrm{ss}}$ interface).

The concentration of $\mathrm{Ti}$ in $\mathrm{TiCu}_{4}$ at the boundary is considered as the lowest $\left(x_{\mathrm{Ti}, \mathrm{min}}^{\mathrm{Ti}_{4}}=0.194\right)$ in its stoichiometric range. According to Eq. $(5), c_{\mathrm{Ti} \text {, min }}^{\mathrm{TiCu}_{4}}$ is $1.50 \times 10^{22}$ atoms $/ \mathrm{cm}^{3}$ using the density from ref. ${ }^{22}$. By integration of Eq. (8), the thickness of $\mathrm{TiCu}_{4}$ layer $(w)$ can be expressed in terms of time $(t)$,

$$
w=w_{0}-2 \frac{c_{\mathrm{Ti}, \max }^{\mathrm{Cu}_{\mathrm{ss}}}}{c_{\mathrm{Ti}, \min }^{\mathrm{TiCu}_{4}}-c_{\mathrm{Ti}, \text { max }}^{\mathrm{Cu}_{\mathrm{ss}}}} \sqrt{\frac{D_{\mathrm{Ti}}^{\mathrm{Cu}}}{\pi} t}
$$

$w_{0}$ is the initial thickness of $\mathrm{TiCu}_{4}$ layer. Equation (9) indicates the average thickness of the $\mathrm{TiCu}_{4}$ decreases linearly with the square root of time. Applying the experimental values of Table 2, the variation of $\mathrm{TiCu}_{4}$ thickness can be expressed as,

$$
w=33.69-6.12 \sqrt{t}(t \text { in hour })
$$

The fitting curve (Fig. 5) exhibits high correlation $\left(R^{2}=0.974\right)$ and gives the titanium diffusion coefficient in copper as $D_{\mathrm{Ti}}^{\mathrm{Cu}}=2.49 \times 10^{-14} \mathrm{~m}^{2} / \mathrm{s}$. From dynamics, the dissolving of $\mathrm{TiCu}_{4}$ layer involves two processes including decomposing reaction $\left(\mathrm{TiCu}_{4} \rightarrow \mathrm{Ti}+4 \mathrm{Cu}\right)$ and atomic diffusion. But the calculated $D_{\mathrm{Ti}}^{\mathrm{Cu}}$ in this work is quite similar to the result $\left(6.37 \times 10^{-14} \mathrm{~m}^{2} / \mathrm{s}\right)$ obtained from a pure $\mathrm{Ti} / \mathrm{Cu}$ diffusion couples ${ }^{23}$. This indicates that the kinetics of $\mathrm{TiCu}_{4}$ decomposing reaction is quite fast, which is possible related to the poor thermodynamic stability of $\mathrm{TiCu}_{4}$.

The growth of $\mathrm{TiC}$ layer on graphite is considered as another independent process consuming $\mathrm{TiCu}_{4}$ in seam. Figure 4 shows that decomposing of $\mathrm{TiCu}_{4}$ on graphite side leads to a narrow $\mathrm{Cu}_{\mathrm{ss}}$ layer on $\mathrm{TiC}$ interface. According to ref. ${ }^{24}$ and calculation in this work, the $D_{\mathrm{Ti}}^{\mathrm{Cu}}$ is much higher than the diffusion coefficient of carbon in $\operatorname{TiC}\left(D_{\mathrm{C}}^{\mathrm{TiC}}=12.74 \times 10^{-16} \mathrm{~m}^{2} / \mathrm{s}\right)^{24}$, indicating that the Ti flux in $\mathrm{Cu}_{\mathrm{ss}}$ may satisfy the growth of TiC. Therefore it's assumed the $\mathrm{TiC}$ boundary adjacent to $\mathrm{Cu}_{\mathrm{ss}}$ and all the $\mathrm{Cu}_{\mathrm{ss}}$ layer have saturated $\mathrm{Ti}$ in their phases. The concentration difference within $\mathrm{TiC}$ layer can be considered to represent the average compositional gradient in this phase. Figure 6a shows the Ti concentration profile of this reaction system. In this figure, $x_{1}$ and $x_{2}$ stand for the location of $\mathrm{TiC} / \mathrm{Cu}_{\mathrm{ss}}$ boundary and $\mathrm{Cu}_{\mathrm{ss}} / \mathrm{TiCu}_{4}$ boundary, respectively. At the beginning of solid diffusion $(t=0)$, $\mathrm{TiCu}_{4}$ layer directly contacts with $\mathrm{TiC}$, the thickness of $\mathrm{Cu}_{\mathrm{ss}}$ is zero, thus $x_{1}=x_{2}$. At time $t=t_{1}$, $\mathrm{TiCu}_{4}$ layer degrades to location $x_{2}$ while TiC layer grows to location $x_{1}$. The decomposing rate of $\mathrm{TiCu}_{4}$ on graphite side can be derived from the growth rate of TiC. Previous investigations have proved that the diffusion coefficient of carbon is far more higher than that of titanium in $\mathrm{TiC}^{24}$. So in this case, it's assumed the growth of TiC layer is dominant by carbon diffusion from graphite interface to $\mathrm{TiC} / \mathrm{TiCu}_{4}\left(\right.$ or $\left.\mathrm{Cu}_{\mathrm{ss}}\right)$ interface. Additionally, the diffusion of carbon in $\mathrm{TiCu}_{4}$ and $\mathrm{Cu}_{\mathrm{ss}}$ is neglected due to the extremely limited solubility of carbon in the two phases. The initial and boundary conditions can be written as:

Initial condition $(t=0)$

$$
x_{1}=x_{2}
$$

Boundary conditions $(t \geq 0)$ 
(a)

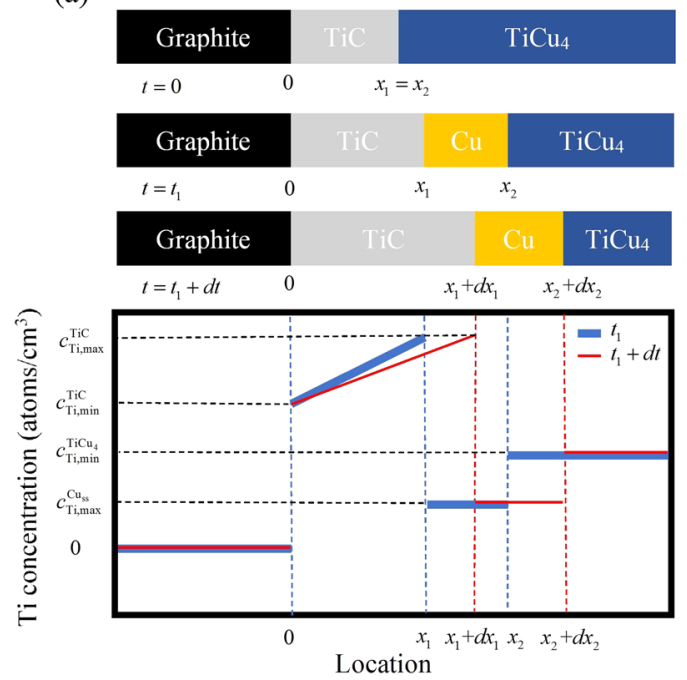

(b)

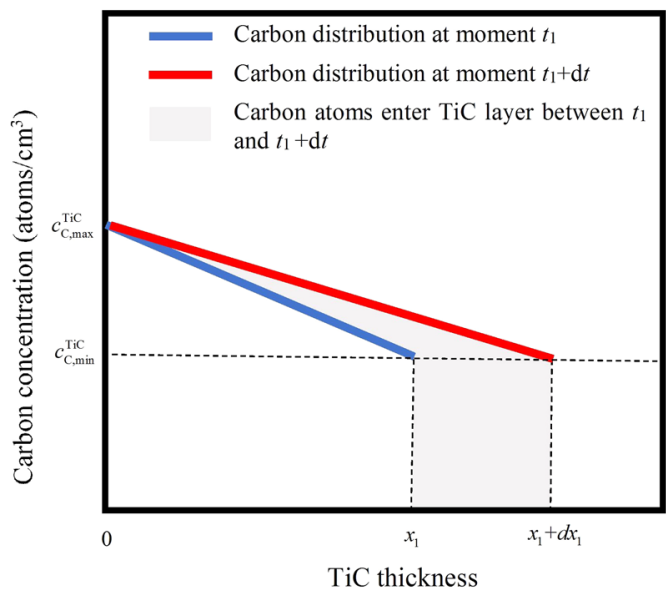

Figure 6. (a) Schematic of reaction layers formed during Ti diffusion in $\mathrm{Cu}_{\mathrm{ss}}$. (b) Carbon concentration distribution in TiC layer from $t_{1}$ to $t_{1}+d t$.

$$
\begin{gathered}
c(t, x=0)=c_{\mathrm{C}, \text { max }}^{\mathrm{TiC}} \\
c\left(t, x=x_{1}(t)\right)=c_{\mathrm{C}, \min }^{\mathrm{TiC}} \\
J_{\mathrm{C}}(t, x=0)=D_{\mathrm{C}}^{\mathrm{TiC}} \frac{c_{\mathrm{C}, \max }^{\mathrm{TiC}}-c_{\mathrm{C}, \min }^{\mathrm{TiC}}}{x_{1}(t)}
\end{gathered}
$$

Here $c_{\mathrm{C}, \max }^{\mathrm{TiC}}$ and $c_{\mathrm{C}, \min }^{\mathrm{TiC}}$ are the maximum $\left(48.5\right.$ at. $\%, 4.81 \times 10^{22}$ atoms $\left./ \mathrm{cm}^{3}\right)$ and minimum $(38.8$ at. $\%$, $3.85 \times 10^{22}$ atoms $/ \mathrm{cm}^{3}$ ) carbon atom concentration in TiC at $860^{\circ} \mathrm{C}$ according to Ti-C binary diagram ${ }^{21}$ and $\mathrm{TiC}$ density $\left(\rho_{\mathrm{TiC}}=4.93 \mathrm{~g} / \mathrm{cm}^{3}\right)^{24}$. Figure $6 \mathrm{~b}$ shows the changing of carbon concentration in TiC within time $d t$. By using conservation of carbon atoms, the TiC growth can be given as:

$$
\frac{c_{\mathrm{C}, \max }^{\mathrm{TiC}}-c_{\mathrm{C}, \text { min }}^{\mathrm{TiC}}}{2} d x_{1}+c_{\mathrm{C}, \text { min }}^{\mathrm{TiC}} d x_{1}=D_{\mathrm{C}}^{\mathrm{TiC}} \frac{c_{\mathrm{C}, \max }^{\mathrm{TiC}}-c_{\mathrm{C}, \min }^{\mathrm{TiC}}}{x_{1}} d t
$$

Rearranging Eq. (15)

$$
x_{1} d x_{1}=2 D_{\mathrm{C}}^{\mathrm{TiC}} \frac{c_{\mathrm{C}, \max }^{\mathrm{TiC}}-c_{\mathrm{C}, \text { min }}^{\mathrm{TiC}}}{c_{\mathrm{C}, \text { max }}^{\mathrm{TiC}}+c_{\mathrm{C}, \text { min }}^{\mathrm{TiC}}} d t
$$

The expression of $\mathrm{TiC}$ layer front location $\left(x_{1}\right)$ as a function of time can be obtained by integration of Eq. (16) with an initial position $x_{1}(t=0)=0.53 \mu \mathrm{m}$ (Table 2$)$.

$$
x_{1}=\sqrt{4 D_{\mathrm{C}}^{\mathrm{TiC}} \frac{c_{\mathrm{C}, \text { max }}^{\mathrm{TiC}}-c_{\mathrm{C}, \text { min }}^{\mathrm{TiC}}}{c_{\mathrm{C}, \text { max }}^{\mathrm{TiC}}+c_{\mathrm{C}, \text { min }}^{\mathrm{TiC}}} t+\left(x_{1}(t=0)\right)^{2}}
$$

By fitting the experimental results shown in Fig. 7 to Eq. (17), it's obtained that

$$
x_{1}=\sqrt{1.046 t+0.277} t \text { in hour }\left(R^{2}=0.994\right)
$$

The diffusion coefficient of carbon in $\mathrm{TiC}\left(D_{\mathrm{C}}^{\mathrm{TiC}}\right)$ is given as $6.54 \times 10^{-16} \mathrm{~m}^{2} / \mathrm{s}$. The result in this work is similar to the reported value $12.74 \times 10^{-16} \mathrm{~m}^{2} / \mathrm{s}$ at $860^{\circ} \mathrm{C}^{24}$. The small deviation of the two values may come from the neglect of carbon diffusion in $\mathrm{Cu}_{\mathrm{ss}}$ in this work, since small quantity of nano TiC particles indeed precipitate nearby the continuous $\mathrm{TiC}$ layer, which is difficult to be taken into the thickness of TiC layer equivalently.

Based on the growth kinetics of $\mathrm{TiC}$, the change of Ti concentration within $\mathrm{TiC}$ from time $t_{1}$ to $t_{1}+d t$ can be approximate to the profile shown in Fig. 6a. The quantity of $\mathrm{Ti}$ atoms migrated to $\mathrm{TiC}$ is given by:

$$
\left[\frac{1}{2}\left(c_{\mathrm{Ti}, \text { min }}^{\mathrm{TiC}}+c_{\mathrm{Ti}, \text { max }}^{\mathrm{TiC}}\right)\left(x_{1}+d x_{1}\right)-\frac{1}{2}\left(c_{\mathrm{Ti}, \text { min }}^{\mathrm{TiC}}+c_{\mathrm{Ti}, \text { max }}^{\mathrm{TiC}}\right) x_{1}\right] \cdot S=\frac{1}{2}\left(c_{\mathrm{Ti}, \text { min }}^{\mathrm{TiC}}+c_{\mathrm{Ti}, \text { max }}^{\mathrm{TiC}}\right) d \mathrm{x}_{1} \cdot S
$$




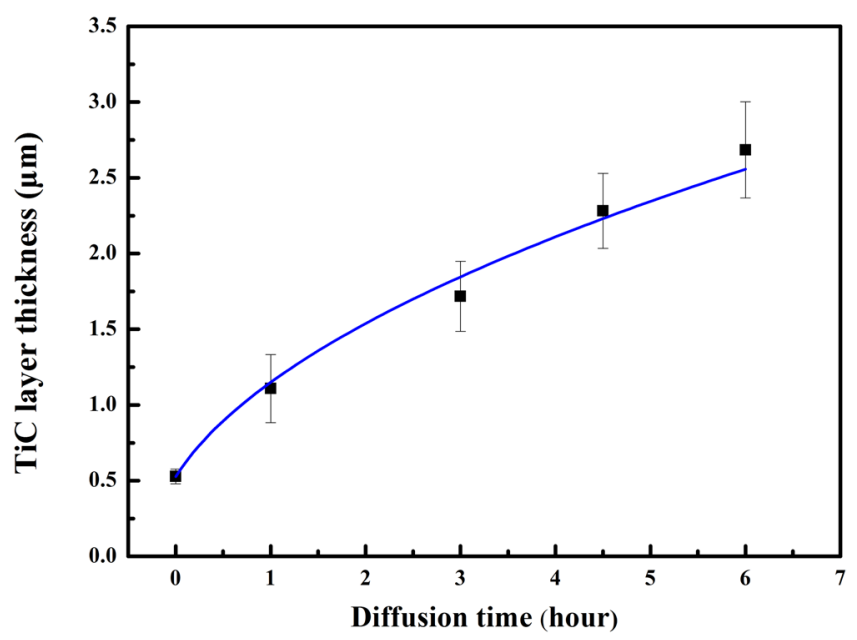

Figure 7. TiC layer thickness as a function of holding time at $860^{\circ} \mathrm{C}$.

(a)

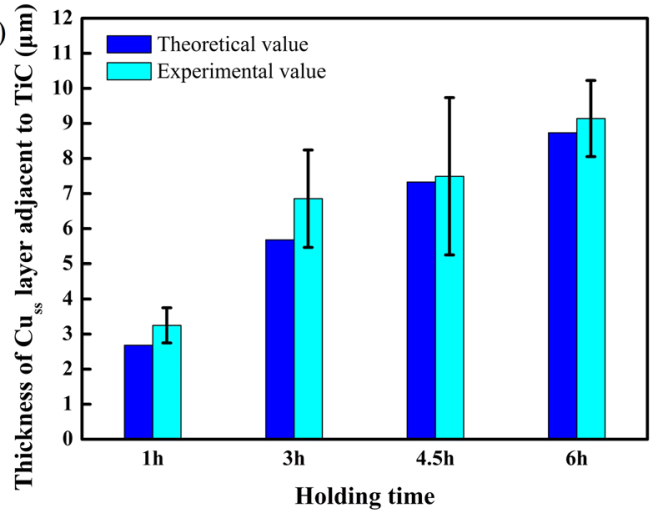

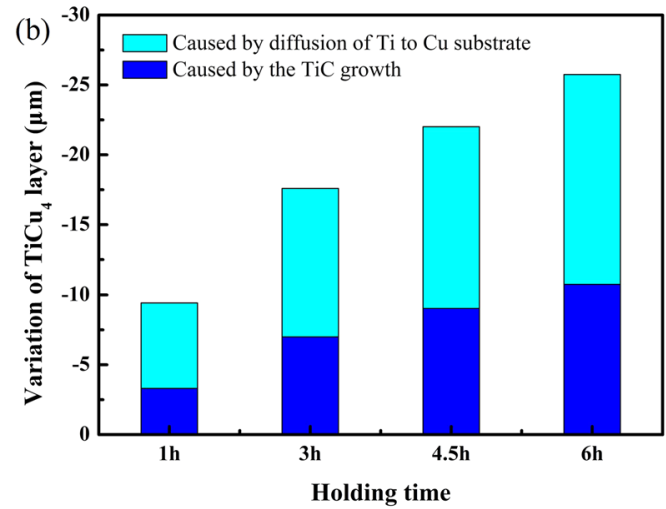

Figure 8. (a) Comparison of theoretical and experimental $\mathrm{Cu}_{\mathrm{ss}}$ thickness as a function of holding time at $860^{\circ} \mathrm{C}$. (b) Variation of $\mathrm{TiCu}_{4}$ layer as a function of holding time at $860^{\circ} \mathrm{C}$.

$\mathrm{S}$ is a layer surface area. Applying the rule of Ti atom conservation at $x_{1}$ and $x_{2}$, the following is obtained:

$$
\left(c_{\mathrm{Ti}, \min }^{\mathrm{TiCu}_{4}}-c_{\mathrm{Ti}, \text { max }}^{\mathrm{Cu}_{\mathrm{ss}}}\right) d x_{2}+c_{\mathrm{Ti}, \text { max }}^{\mathrm{Cu}_{\mathrm{ss}}} d x_{1}=\frac{1}{2}\left(c_{\mathrm{Ti}, \min }^{\mathrm{TiC}}+c_{\mathrm{Ti}, \max }^{\mathrm{TiC}}\right) d x_{1}
$$

Rearrange Eq. (20):

$$
\frac{d x_{2}}{d t}=\frac{1}{2} \frac{\left(c_{\mathrm{Ti}, \min }^{\mathrm{TiC}}+c_{\mathrm{Ti}, \max }^{\mathrm{TiC}}-2 c_{\mathrm{Ti}, \text { max }}^{\mathrm{Cu}_{\mathrm{ss}}}\right)}{\left(c_{\mathrm{Ti}, \text { min }}^{\mathrm{TiCu}}-c_{\mathrm{Ti}, \text { max }}^{\mathrm{Cu}_{\mathrm{ss}}}\right)} \frac{d x_{1}}{d t}
$$

By integration of Eq. (21), it is obtained that

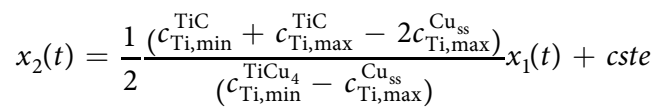

Incorporating Eqs (22 and 18) and the initial condition $x_{2}(t=0)=0.53 \mu \mathrm{m}$, the movement of $\mathrm{TiCu}_{4}$ boundary $\left(x_{2}\right)$ on the graphite side can be expressed as a function of time:

$$
x_{2}(t)=5.29 \sqrt{1.046 t+0.277}-2.25 t \text { in hour }
$$

Based on Eqs (18 and 23), the thickness of $\mathrm{Cu}_{\mathrm{ss}}\left(w_{\mathrm{Cu}}(t)\right)$ adjacent to TiC layer can be derived from the difference between $x_{1}(t)$ and $x_{2}(t)$ :

$$
w_{\mathrm{Cu}}(t)=4.29 \sqrt{1.046 t+0.277}-2.25 t \text { in hour }
$$

Figure 8a shows the predicted thickness of $\mathrm{Cu}_{\mathrm{ss}}$ with various holding time at $860^{\circ} \mathrm{C}$ compared with the experimental data. A reasonable agreement between the predicted data and experimental data can be seen. For all the samples, the experimental data is $2 \% \sim 17 \%$ higher than the calculated one in $\mathrm{Cu}_{\mathrm{ss}}$ thickness. The small discrepancy 

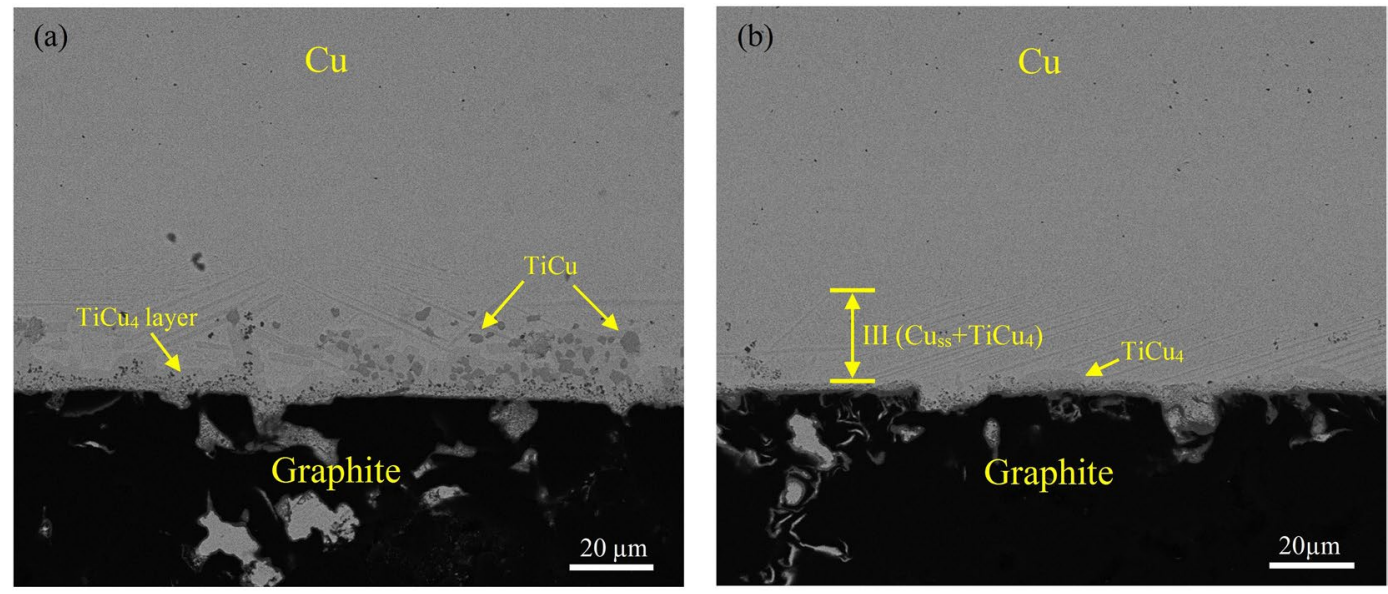

Figure 9. Backscattered electron micrographs of graphite/Ti $(6 \mathrm{~mm} \times 6 \mathrm{~mm} \times 20 \mu \mathrm{m}) / \mathrm{Cu}$ joints prepared by (a) brazing at $920^{\circ} \mathrm{C}$ for $5 \mathrm{~min}$ with pressure of $8.9 \mathrm{kPa}$ and (b) TLP bonding (heat to $920^{\circ} \mathrm{C}$ for $5 \mathrm{~min}$ and isothermally held at $860^{\circ} \mathrm{C}$ for $1 \mathrm{~h}$ ) with pressure of $8.9 \mathrm{kPa}$.

is probably due to neglect of $\mathrm{TiC}$ particles nearby TiC layer. Though the quantity is small, the growth of these particles with large specific surface area may contribute to consuming more $\mathrm{TiCu}_{4}$ by solid diffusion.

Taking account of diffusion process in $\mathrm{Cu}$ substrate (Eq. (10)) and competing reactions with TiC (Eq. (23)), the final equation represents the variation of $\mathrm{TiCu}_{4}$ layer $(\Delta w)$ can be expressed as follows:

$$
\Delta w=5.29 \sqrt{1.046 t+0.277}-2.78+6.12 \sqrt{t} t \text { in hour }
$$

Figure $8 \mathrm{~b}$ shows the predicted variation of $\mathrm{TiCu}_{4}$ layer as a function of time. Apparently, the quantity of $\mathrm{TiCu}_{4}$ consumed on diffusing in $\mathrm{Cu}$ substrate is prominent due to the high diffusion coefficient of Ti in $\mathrm{Cu}$. The part consumed on $\mathrm{TiC}$ growth is around one third of the total at the beginning and it gradually increases with prolonging time. The result here also indicates that the most effective stage to eliminate $\mathrm{TiCu}_{4}$ is at the beginning of solid diffusion. For example, the average recession rate of $\mathrm{TiCu}_{4}$ layer within 1 hour $\left(v_{1}=9.43 \mu \mathrm{m} / \mathrm{h}\right)$ is more than twice of that within 6 hours $\left(v_{6}=4.29 \mu \mathrm{m} / \mathrm{h}\right)$. Considering excessive diffusion of Ti may change the property of $\mathrm{Cu}$ substrate (such as elastic modulus, hardness and thermal conductivity) and thicken TiC layer, rational controlling the time of solid diffusion process is not only beneficial for joining economy but also for joint property.

Optimization of TLP bonding for copper/graphite joints. Above section reveals that solid state diffusion is an effective but time-intensive approach to eliminate residual $\mathrm{Ti}$ - $\mathrm{Cu}$ compound layer in seam. In order to maintain good performance of joints and remove the time impediment, a combination of liquid alloy extrusion and solid state diffusion is used in the optimized joining process. Figure 9a shows the interfacial microstructure of graphite/Ti/Cu joint by brazing at $920^{\circ} \mathrm{C}$ for $5 \mathrm{~min}$ with an increased pressure of $8.9 \mathrm{kPa}$. The large scale liquid flow driven by extrusion during brazing can be evidenced by the fluctuant $\mathrm{TiCu}_{4}$ layer as well as the positions of $\mathrm{TiCu}$ compounds which have been pushed to the graphite interface (see Fig. 9a). The thickness of $\mathrm{TiCu}_{4}$ layer in this condition is $9.8 \pm 3.4 \mu \mathrm{m}$ thick, less than one third of the one without extrusion (as shown in Fig. 4a). According to the model proposed above, this $\mathrm{TiCu}_{4}$ layer can be dissipated within 1 hour by solid state diffusion. Figure $9 \mathrm{~b}$ shows the interfacial microstructure of graphite/Ti/Cu joint by TLP bonding (brazed at $920^{\circ} \mathrm{C}$ for $5 \mathrm{~min}$ and then solid diffusion at $860^{\circ} \mathrm{C}$ for $1 \mathrm{~h}$ with pressure of $8.9 \mathrm{kPa}$ ). It is found that the residual $\mathrm{TiCu}_{4}$ is nearly all eliminated. In addition, the quantity of stable $\mathrm{TiCu}$ is also decreased significantly after solid state diffusion. This is probably due to the competing reactions between $\mathrm{TiCu}$ and $\mathrm{TiC}$ : as $\mathrm{TiCu}$ compounds are pushed to the graphite interface, the more stable $\mathrm{TiC}$ tends to grow by using $\mathrm{Ti}$ atoms dissolved from $\mathrm{TiCu}$ compounds during solid diffusion. By comparing Fig. 9a,b, it is concluded that the optimized TLP bonding with combination of liquid alloy extrusion and solid state diffusion is a feasible way to eliminate $\mathrm{Ti}-\mathrm{Cu}$ compounds in a short time. The shear strengths of joints by brazing and the optimized TLP bonding are $24 \pm 6 \mathrm{MPa}$ and $29 \pm 3 \mathrm{MPa}$, respectively. The load-displacement curves (Fig. 10) indicate both of the joints are brittle fractured. The extra stage of curve B after the maximum load is caused by the coarse fracture surface which may hinder the relative motion of the two broken parts. It's inferred the microcracks in Ti-Cu compound layer may result in the failure of brazing joints at lower load. As for the joint by TLP bonding, though the residual stress is inevitable, defect is prevented due to the superior microstructure. So the joint has higher load bearing capability.

\section{Conclusion}

For brazing of graphite and copper with $\mathrm{Ti}$ interlayer, the continuous $\mathrm{TiCu}_{4}$ layer is believed to be the most dangerous phase due to its cracking tendency under stress. In this work, a TLP bonding method with a diffusion process below melting point is proposed to eliminate $\mathrm{Ti}-\mathrm{Cu}$ compounds in seam. A model for the degradation of $\mathrm{TiCu}_{4}$ layer is developed considering the simultaneous diffusion on both sides, one is the Ti diffusion in $\mathrm{Cu}$ substrate and the other is the Ti diffusion towards TiC layer. The latter is controlled by the growth kinetics of TiC. 


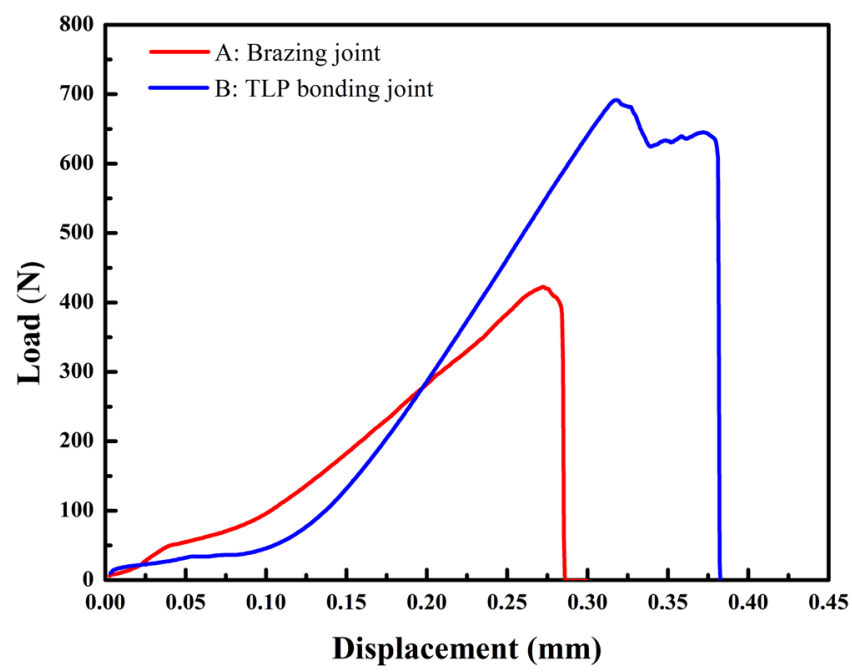

Figure 10. Load-displacement curves of brazing joint and optimized TLP bonding joint.

\begin{tabular}{|l|l|l|l|l|l|l|l|}
\hline Materials & Graphite & Copper \\
\hline \multirow{2}{*}{ Compositions (wt.\%) } & \multirow{2}{*}{$\mathrm{C} \geq 99.99$} & $\mathrm{Cu}+\mathrm{Ag}$ & $\mathrm{Fe}$ & $\mathrm{Ni}$ & $\mathrm{S}$ & $\mathrm{O}$ & Others \\
\cline { 3 - 8 } & & 99.90 & 0.005 & 0.005 & 0.005 & 0.006 & 0.079 \\
\hline Density $\left(\mathrm{g} / \mathrm{cm}^{3}\right)$ & 1.85 & 8.93 & & & & & \\
\hline $\mathrm{CTE}(/ \mathrm{K})$ & $3.9 \times 10^{-6}$ & $16.5 \times 10^{-6}$ & 125 & & & & \\
\hline Elastic modulus $(\mathrm{GPa})$ & 10 & - & 52 & - & & & \\
\hline Flexural strength $(\mathrm{MPa})$ & 52 & &
\end{tabular}

Table 3. Chemical compositions and mechanical properties of the materials.

Based on this model, the TLP bonding is optimized to realize a Ti-Cu compound layer free joint in a short time. The shear strength of joints prepared by this method increases by $20.8 \%$ compared with that of brazing joints.

\section{Methods}

Sample preparation. Graphite (Beijing Electrical Carbon Co., Ltd.) and copper (Foshan Huaru Copper Co., Ltd.) are used as substrate materials to be joined in this work. The chemical compositions and mechanical properties are listed in Table 3. Graphite was cut into $7 \mathrm{~mm} \times 7 \mathrm{~mm} \times 2.5 \mathrm{~mm}$ pieces for microstructure observation and $15 \mathrm{~mm} \times 10 \mathrm{~mm} \times 3 \mathrm{~mm}$ pieces for shear tests. Copper was cut into $5 \mathrm{~mm} \times 5 \mathrm{~mm} \times 2.5 \mathrm{~mm}$ pieces. The bonding surfaces of graphite and copper were ground on SiC abrasive papers (2000\#) and then polished with $1 \mu \mathrm{m}$ diamond pastes. All samples were ultrasonically cleaned in acetone for $10 \mathrm{~min}$. Joining process was carried out in a furnace with vacuum better than $1.3 \times 10^{-3} \mathrm{~Pa}$ (oxygen partial pressure of $10^{-4} \mathrm{~Pa}$ ). Three joining methods were carried out in this work. The first one was brazing. A $50 \mu \mathrm{m}$ thick Ti foil was cut into $6 \mathrm{~mm} \times 6 \mathrm{~mm}$ and sandwiched between graphite and copper with normal load of $5.9 \mathrm{kPa}$. The assembly was kept in graphite jig and heated to $920^{\circ} \mathrm{C}$ at $10^{\circ} \mathrm{C} / \mathrm{min}$, isothermally held for $10 \mathrm{~min}$, then slowly cooled to room temperature at $10^{\circ} \mathrm{C} /$ $\mathrm{min}$. The second one was TLP bonding for Ti-Cu IMCs degradation kinetics investigation. In order to limit the flow of filler alloy, a smaller Ti foil $(4 \mathrm{~mm} \times 4 \mathrm{~mm} \times 20 \mu \mathrm{m})$ was sandwiched between graphite and copper with normal load of $5.9 \mathrm{kPa}$. The assembly was heated to $920^{\circ} \mathrm{C}$ at $10^{\circ} \mathrm{C} / \mathrm{min}$, isothermally held for $5 \mathrm{~min}$, then cooled to $860^{\circ} \mathrm{C}$, isothermally held for various times $(0 \mathrm{~h}, 1 \mathrm{~h}, 3 \mathrm{~h}, 4.5 \mathrm{~h}$ and $6 \mathrm{~h})$, and finally cooled to room temperature at $10^{\circ} \mathrm{C} / \mathrm{min}$. The third one was an optimized TLP bonding. A Ti foil $(6 \mathrm{~mm} \times 6 \mathrm{~mm} \times 20 \mu \mathrm{m})$ was used as filler alloy with increased load of $8.9 \mathrm{kPa}$. The assembly was heated to $920^{\circ} \mathrm{C}$ at $10^{\circ} \mathrm{C} / \mathrm{min}$, isothermally held for $5 \mathrm{~min}$, then cooled to $860^{\circ} \mathrm{C}$, isothermally held for $1 \mathrm{~h}$, and finally cooled to room temperature at $10^{\circ} \mathrm{C} / \mathrm{min}$.

Characterization. The microstructure, chemistry and morphology were investigated by scanning electron microscopy (SEM, FEI Quanta 400, Eindhoven, Netherlands) equipped with an energy dispersive X-ray spectroscopy (EDS). The phases in joints were identified by an X-ray diffraction method (XRD, PANalytical Empyrean, Netherlands). The specimens for XRD test were polished layer by layer to expose the filler alloy nearby graphite interface. The thickness measurements of different phases ( $\mathrm{TiCu}_{4}, \mathrm{TiC}$ and copper solid solution layers) were made from SEM micrographs of metallographically polished samples. These measurements were done at 10 equally spaced locations on the micrographs. The shear strength of joints at room temperature was examined using a universal testing machine (Instron-1186, Grove City, PA) with a displacement rate of $0.5 \mathrm{~mm} / \mathrm{min}$. The scheme of shear testing was reported in ref. ${ }^{25}$. The strength was calculated by dividing the maximum load by the surface of the joint. The tested values for each experimental condition were an average of at least six measurements. 


\title{
Data Availability Statement
}

The datasets generated during and/or analysed during the current study are available from the corresponding author on reasonable request.

\section{References}

1. Zhang, M. et al. Influence of cryogenic thermal cycling treatment on the thermophysical properties of carbon/carbon composites between room temperature and $1900^{\circ}$ C. J. Mater. Sci. Technol. 34, 409-415 (2018).

2. Wissler, M. Graphite and carbon powders for electrochemical applications. J. Power Sources 156, 142-150 (2006).

3. Delhaes, P. Chemical vapor deposition and infiltration processes of carbon materials. Carbon 40, 641-657 (2002)

4. Tang, S. \& Hu, C. Design, preparation and properties of carbon fiber reinforced ultra-high temperature ceramic composites for aerospace applications: A review. J. Mater. Sci. Technol. 33, 117-130 (2017).

5. Wu, L., Nagatsuka, K. \& Nakata, K. Direct joining of oxygen-free copper and carbon-fiber-reinforced plastic by friction lap joining. J. Mater. Sci. Technol. 34, 192-197 (2018).

6. Appendino, P. et al. Joining of C/C composites to copper. Fusion Eng. Des. 66-68, 225-229 (2003).

7. Song, X. et al. A novel metallization process for soldering graphite to copper at low temperature. J. Alloy. Compd. 696, 1199-1204 (2017).

8. Zhang, J., Wang, T. \& Liu, C. Effect of brazing temperature on microstructure and mechanical properties of graphite/copper joints. Mat. Sci. Eng. a-Struct. 594, 26-31 (2014).

9. Yang, L., Shen, P., Lin, Q., Qiu, F. \& Jiang, Q. Wetting of porous graphite by Cu-Ti alloys at 1373 K. Mater. Chem. Phys. 124, 499-503 (2010).

10. Mao, Y. et al. Brazing of graphite to Cu with Cu50TiH2 + C composite filler. J. Mater. Sci. 51, 1671-1679 (2016).

11. Bisio, M. et al. Manufacturing and testing in reactor relevant conditions of brazed plasma facing components of the ITER divertor. Fusion Eng. Des. 75-79, 277-283 (2005).

12. He, P., Zhang, J., Zhou, R. \& Li, X. Diffusion bonding technology of a titanium alloy to a stainless steel web with an Ni interlayer. Mater. Charact. 43, 287-292 (1999).

13. Guo, S. et al. Study on strengthening mechanism of Ti/Cu electron beam welding. Mater. Design 121, 51-60 (2017).

14. Chen, G., Zhang, B., Liu, W. \& Feng, J. Influence of electron-beam superposition welding on intermetallic layer of Cu/Ti joint. Trans. Nonferrous Met. Soc. China 22, 2416-2420 (2012).

15. Hong, S., Bartlow, C., Reynolds, T., McKeown, J. T. \& Glaeser, A. M. Ultrarapid transient-liquid-phase bonding of $\mathrm{Al}_{2} \mathrm{O}_{3}$ ceramics. Adv. Mater. 20, 4799-4803 (2008).

16. Cook, G. O. \& Sorensen, C. D. Overview of transient liquid phase and partial transient liquid phase bonding. J. Mater. Sci. 46, 5305-5323 (2011).

17. Liang, Y., Wang, H., Yang, Y., Wang, Y. \& Jiang, Q. Evolution process of the synthesis of TiC in the Cu-Ti-C system. J. Alloy. Compd. 452, 298-303 (2008).

18. Zhong, Z., Zhou, Z. \& Ge, C. Brazing of doped graphite to Cu using stress relief interlayers. J. Mater. Process. Tech. 209, 2662-2670 (2009).

19. Asthana, R. \& Singh, M. Joining of $\mathrm{ZrB}_{2}$-based ultra-high-temperature ceramic composites using Pd-based braze alloys. Scr. Mater. 61, 257-260 (2009).

20. Qiu, Q., Wang, Y., Yang, Z. \& Wang, D. Microstructure and mechanical properties of $\mathrm{Al}_{2} \mathrm{O}_{3}$ ceramic and Ti6Al4V alloy joint brazed with inactive Ag-Cu and Ag-Cu+ B. J. Eur. Ceram. Soc. 36, 2067-2074 (2016).

21. Jarfors, A. E. W. The influence of carbon on the phases in the copper-titanium system and their precipitation. J. Mater. Sci. 34, 4533-4544 (1999).

22. Zhu, Y., Yan, M., Zhang, Y. \& Zhang, C. First-principles investigation of structural, mechanical and electronic properties for Cu-Ti intermetallics. Comput. Mater. Sci. 123, 70-78 (2016).

23. Iljima, Y., Ken-Ichi, H. \& Hoshino, K. Diffusion of titanium in copper. Metall. Trans. A, Phys. Metall. Mater. Sci. 8A, 997-1001 (1977).

24. Miriyev, A., Sinder, M. \& Frage, N. Thermal stability and growth kinetics of the interfacial TiC layer in the Ti alloy/carbon steel system. Acta Mater. 75, 348-355 (2014).

25. He, P. et al. Diffusion bonding of $\mathrm{ZrB}_{2}-\mathrm{SiC} / \mathrm{Nb}$ with in situ synthesized TiB whiskers array. J. Eur. Ceram. Soc. 32, 4447-4454 (2012).

\section{Acknowledgements}

The authors gratefully acknowledge the financial support from National Natural Science Foundation of China (NSFC, Grant Number 51605499 and 11504438), Natural Science Foundation of Guangdong Province (2015A030310348) and University Basal Research Fund (171gpy35 and 171gpy33).

\section{Author Contributions}

W. Yang and L. Xing proposed and guided the overall project. J. Lin performed the experiments, analyzed the results, and wrote the main manuscript text. M. Huang prepared the sample materials and measured the experimental data. All authors reviewed the manuscript.

\section{Additional Information \\ Competing Interests: The authors declare no competing interests.}

Publisher's note: Springer Nature remains neutral with regard to jurisdictional claims in published maps and institutional affiliations.

\begin{abstract}
Open Access This article is licensed under a Creative Commons Attribution 4.0 International License, which permits use, sharing, adaptation, distribution and reproduction in any medium or format, as long as you give appropriate credit to the original author(s) and the source, provide a link to the Creative Commons license, and indicate if changes were made. The images or other third party material in this article are included in the article's Creative Commons license, unless indicated otherwise in a credit line to the material. If material is not included in the article's Creative Commons license and your intended use is not permitted by statutory regulation or exceeds the permitted use, you will need to obtain permission directly from the copyright holder. To view a copy of this license, visit http://creativecommons.org/licenses/by/4.0/.
\end{abstract}

(C) The Author(s) 2018 